\title{
The Unemployment Volatility Puzzle: A Note on the Role of Reference Points
}

\author{
Vincent Boitier \\ Centre d'Economie de la Sorbonne, Université Paris 1 Panthéon-Sorbonne, Paris, France \\ Email: vincent.boitier@univ-paris1.fr
}

Received 23 January 2015; accepted 9 February 2015; published 12 February 2015

Copyright (C) 2015 by author and Scientific Research Publishing Inc.

This work is licensed under the Creative Commons Attribution International License (CC BY). http://creativecommons.org/licenses/by/4.0/

c) (i) Open Access

\begin{abstract}
This theoretical note aims at studying the role of reference points in generating unemployment volatility. For this purpose, I introduce the notion of reference points in a standard MortensenPissarides model. I obtain two results. First, I find that the obtained model is similar to the one found by Pissarides in 2009. Second, I show that the introduction of reference points can increase significantly unemployment volatility through a mechanism à la Hagerdorn and Manovskii.
\end{abstract}

\section{Keywords}

\section{Reference Points, Unemployment Volatility, Job Matching, Sequential Bargaining}

\section{Introduction}

Economic studies and laboratory experiments clearly show that reference points play a fundamental role in (wage) negotiations (see, within a large literature, [1]-[3]). Indeed, it is demonstrated that agents evaluate offers and outcomes as gains and losses relative to some reference points. Therefore, by affecting preferences, these points impact both the process and the outcome of bilateral bargaining.

Moreover, a pervasive challenge in macroeconomics is to understand why the standard Mortensen-Pissarides (hereafter MP) model cannot generate the volatility of the unemployment rate observed in US data. This is the so-called Shimer puzzle. Several solutions have been proposed to solve this puzzle. For example, [4] pleads in favor of high unemployment benefits while [5] considering additional matching costs.

The aim of this theoretical note is to draw a link between reference points and the unemployment volatility puzzle. For this purpose, I consider a simple MP model with exogenous separations, reference points and where the partition of the surplus is no longer derived by a Nash bargaining game. It is determined by a sequential bargaining game where the outcome of this new negotiation process is evaluated relative to a reference point. I then deduce the new wage equation and the new associated job creation. I find that the obtained model is 
equivalent to the one found by [5]. I also show that the presence of reference points raises considerably the unemployment volatility through a mechanism à la Hagerdorn and Manovskii. Indeed, I demonstrate that reference points can lower the firm's profit and increase wage share by improving the outside option of the worker. Thus, this short article adds reference points to the list of solutions to the Shimer puzzle.

Notice finally that this is not the first framework that integrates reference dependence in a MP model. In a recent working paper, [6] studies the properties of a dynamical model with search and matching frictions and with a reference point in the productivity process of the firm. However, their model is quite different from the one developed in this paper. Among other things, it features wage stickiness, it amplifies unemployment volatility via a new mechanism independent from [4] and it does not aim at solving the Shimer puzzle.

This note is organized as follows. Section 2 describes the search and matching model with reference points. Section 3 provides a conclusion.

\section{Search and Matching Model with Reference Points}

The model considered hereafter is the standard search and matching model with reference points and sequential bargaining.

\subsection{Basic Environment}

I follow [7]. Let $U$ and $W$ be the asset values of being unemployed and being employed. These asset values are given by:

$$
r U=z+f(\theta)(W-U)
$$

and

$$
r W=\omega+s(U-W)
$$

with $r$ the risk-free interest rate, $z$ the unemployment benefits, $s$ the separation rate and $f(\theta)=\theta q(\theta)$ the job finding rate. Let $V$ and $J$ be the asset values of a vacancy and a filled job. These asset values are defined as:

$$
r V=-c+q(\theta)(J-V)
$$

and

$$
r J=p-\omega-s J
$$

with $c$ the cost of a vacancy, $p$ the productivity of workers, $\omega$ the wage and $q(\theta)$ the job filling rate. Using Equation (3), Equation (4) and the free entry condition (i.e. $V=0$ ), the job creation equation is determined as:

$$
\frac{p-\omega}{r+s}=\frac{c}{q(\theta)}
$$

Furthermore, notice that the unemployment rate of the economy is given by the following standard Beveridge curve:

$$
u=\frac{s}{s+f(\theta)}
$$

\subsection{Wage Determination}

Once the match is made, employer and employee have to negotiate over the partition of the surplus defined as $S=W-U+J-V$ according to a sequential bargaining game. In the first stage of the game, one player is randomly chosen to make a take-it or leave-it offer. The probability for the worker to be drawn is assumed to be $\beta$ while the probability for the firm is $1-\beta$. If the offer is accepted by the opponent, the game ends. Conversely, if the offer is rejected, the game goes on to the next period where a player is again randomly selected and bargaining begins again. Note that the time interval separating one period from another is $\tau$. If players disagree forever, their payoffs are equal to zero. If players agree on a partition of the surplus, they enjoy the following 
utility function used by $[8]^{1}$ :

$$
u_{i}\left(x_{i}, \phi_{i}\right)=x_{i}-\phi_{i}
$$

with $i \in\{W, F\}$ and where $\mathrm{W}$ is the index of the worker such that $x_{W}=W-U, \mathrm{~F}$ is the index of the firm such that $x_{F}=J-V$ and $\phi_{i}$ is the reference point of player $i$. Equation (7) states that the utility of agents depends on the deviation of the value of the agreement from the reference point. In line with prospect theory, this means that outcomes are compared to a reference point that splits the agent preferences into gains and losses (i.e. $u_{i}<0$ for $x_{i}<\phi_{i}$ and $u_{i} \geq 0$ for $x_{i} \geq \phi_{i}$ ). In particular, the reference points are viewed as commitments. It is as if players simultaneously commit, or announce their will, not to accept a surplus share smaller than $\phi_{i}$. However, contrary to prospect theory and for the sake of simplicity, the valuation of gains and losses are symmetric (i.e. no loss aversion) $)^{2}$. Within this environment and noting that employer and employee discount future utilities, the sub-game perfect equilibrium of such a game is:

$$
\left\{\begin{array}{l}
S-x_{W}-\phi_{F}=\mathrm{e}^{-r \tau}\left[\beta\left(S-x_{W}-\phi_{F}\right)+(1-\beta)\left(x_{F}-\phi_{F}\right)\right] \\
S-x_{F}-\phi_{W}=\mathrm{e}^{-r \tau}\left[\beta\left(x_{W}-\phi_{W}\right)+(1-\beta)\left(S-x_{F}-\phi_{W}\right)\right]
\end{array}\right.
$$

if and only if $\phi_{W}+\phi_{F} \leq S$. Otherwise (i.e. if $\phi_{W}+\phi_{F}>S$ ), no agreement exists. Solving system (8) for $x_{W}$ and $x_{F}$ and letting $\tau \rightarrow 0$ leads to:

$$
\left\{\begin{array}{l}
x_{W}=\phi_{W}+\beta\left(S-\phi_{W}-\phi_{F}\right) \\
x_{F}=\phi_{F}+(1-\beta)\left(S-\phi_{W}-\phi_{F}\right)
\end{array}\right.
$$

This is the familiar "split the difference rule": if demands are compatible (i.e. $\phi_{W}+\phi_{F} \leq S$ ), then an agreement is a situation where each agent gets the utility value of its reference point and the remaining fraction of the surplus according to his bargaining power. Reducing system (9) gives the following new sharing rule:

$$
(1-\beta)\left(W-U-\phi_{W}\right)=\beta\left(J-V-\phi_{F}\right)
$$

Using the above sharing rule, the wage satisfies:

$$
\omega=r U+\beta(p-r U)+(r+s)\left[(1-\beta) \phi_{W}-\beta \phi_{F}\right]
$$

Likewise, using Equation (1), the job creation equation and the sharing rule, I obtain:

$$
r U=z+\frac{\beta}{1-\beta} c \theta-\frac{\beta}{1-\beta} f(\theta) \phi_{F}+f(\theta) \phi_{W}
$$

Plugging Equation (12) in Equation (11) yields:

$$
\omega=(1-\beta)\left\{z+[r+s+f(\theta)] \phi_{W}\right\}+\beta\left\{p+c \theta-[r+s+f(\theta)] \phi_{F}\right\}
$$

Equation (13) shows that the worker's reference point increases the wage by raising the reservation wage while the firm's reference point decreases the wage by lowering the expected return of the match. Moreover, observe that if reference points are equal (i.e. $\phi_{W}=\phi_{F}$ ), I end up with the standard wage equation derived from a generalized Nash bargaining game. Finally, the wage equation can be rewritten as:

$$
\omega=(1-\beta) z+\beta(p+c \theta)+[r+s+f(\theta)] H
$$

where $H=(1-\beta) \phi_{W}-\beta \phi_{F}$ can be viewed as an index measuring the relative importance of the worker's reference point. Integrating Equation (14) in Equation (5), the job creation equation becomes:

\footnotetext{
${ }^{1}$ The comparison with [8] stops there since, in [8], the reference points are endogenous and dynamically changing according to the offers previously made by the players. Also note that reference-dependence distorts the bargaining process by introducing fixed-costs only. It does not distort the matching process. However, one should introduce reference-dependent preferences from the Bellman equations. The results would be exactly the same.

${ }^{2}$ It is possible to consider a general utility function such that $u_{i}\left(x_{i}, \phi_{i}\right)=f\left(x_{i}-\eta \phi_{i}\right)$ where $\mathrm{f}$ could exhibit loss aversion. Nonetheless, I assume a linear utility function in order to show that the [5] model is a particular case of this general function.
} 


$$
\frac{p-(1-\beta) z-\beta(p+c \theta)-f(\theta) H}{r+s}=\frac{c}{q(\theta)}+H
$$

\subsection{Comparison with [5]}

[5] considers a search and matching model with additional matching costs. In this setup, the job creation equation is

$$
\frac{p-(1-\beta) z-\beta(p+c \theta)-\beta f(\theta) H}{r+s}=\frac{c}{q(\theta)}+H
$$

and the Beveridge curve is identical to the one in Equation (6). Thus, up to a coefficient $\beta$ in (16), the job creation equation determined by a MP model with reference points is the same as the one determined by a MP model with matching costs. This suggests that these two models generate the same quantitative results. To confirm this intuition, I solve the job creation Equation (15) for the unknown $\theta$ with [5] calibration. I then study the effect of a $1 \%$ productivity shock on the model's unknown by computing the elasticity $\epsilon_{\theta}$ of the tightness index with respect to productivity and the elasticity $\epsilon_{\omega}$ of the wage with respect to productivity. Table 1 gives the results for different values of $H^{3}$. As in [5], the model generates persistent high wage elasticities and an increase in $H$ raises dramatically the volatility of job creation. Especially, the model is able to reproduce the observed volatility of labor market tightness (i.e. $\epsilon_{\theta}=7.56$ ) when $H=0.219$. Since wage stickiness does not matter here, the amplification mechanism is driven by the relative role of workers' reference point. Indeed, for high $H$, the reference point of the worker is larger than the reference point of the firm. This leads to an increase in the wage set by firms because the reservation wage (or the outside option of the worker) is very high. This lowers the firm's surplus and so increases the effect of the productivity shock. Namely, the introduction of reference points in a standard MP model can increase the unemployment volatility through a mechanism developed by $[4]$.

To conclude, contrary to [5] where matching costs are always assumed to be exogenous, it is easy to endogenize reference points in this setting. In this stationary framework, a natural candidate for the worker's reference point is the partition of the surplus received by a worker in the standard MP model. This surplus is equal to 0.438 . Assuming that the firm has no reference point, the reference point of the worker is $\phi_{W}=0.438$ and so $H=0.219$. Using Table 1 , one can observe that the volatility is almost matched, meaning that the introduction of endogenous reference points in a standard MP model is a credible solution to solve the Shimer puzzle.

\section{Conclusions}

In this note, I integrate reference dependent preferences in the wage bargaining of the benchmark MP model. In so doing, I study how reference points affect unemployment volatility. I obtain two results. First, I show that reference points act similarly to matching costs in [5]. Second, I find that these reference points can generate unemployment volatility via a mechanism à la Hagerdorn and Manovskii.

Table 1. Simulations results at different $\mathrm{H}$.

\begin{tabular}{cccc}
\hline$H$ & $c$ & $\epsilon_{\omega}$ & $\epsilon_{\theta}$ \\
\hline 0.000 & 0.356 & 0.98 & 3.66 \\
0.050 & 0.277 & 0.98 & 4.12 \\
0.100 & 0.199 & 0.98 & 4.71 \\
0.150 & 0.120 & 0.98 & 5.51 \\
0.200 & 0.044 & 0.99 & 6.62 \\
0.219 & 0.015 & 0.99 & 7.17
\end{tabular}

Several extensions can be considered. For example, reference points are introduced (in the present article) as a

${ }^{3}$ So far, there is no calibration for $H$ because of lack of empirical evidence. This limit is in line with [5]: "Since we do not have information about how the job creation costs are split between the costs that depend on the duration of vacancies and the costs that do not, we cannot choose one combination over another on the basis of independent evidence" in [5] (p. 1375). 
fixed reduction in utility. This means that there is no loss aversion: the valuation of gains and losses enters symmetrically in the utility function. Therefore, future research should be naturally directed at understanding the effect of reference points that exhibits loss aversion.

\section{Acknowledgements}

I thank the referee for his comments. I also thank Jean Olivier Hairault, Pierrick Clerc, Nicolas Dromel and Antoine Lepetit for their help.

\section{References}

[1] Kahneman, D. (1992) Reference Points, Anchors, Norms, and Mixed Feelings. Organizational Behavior and Human Decision Processes, 51, 296-312. http://dx.doi.org/10.1016/0749-5978(92)90015-Y

[2] Kahneman, D. and Tversky, A. (1979) Prospect Theory: An Analysis of Decision under Risk. Econometrica, 47, 263291. http://dx.doi.org/10.2307/1914185

[3] Koszegi, B. and Rabin, M. (2006) A Model of Reference-Dependent Preferences. Quarterly Journal of Economics, 121, 1133-1166.

[4] Hagerdorn, M. and Manovskii, I. (2008) The Cyclical Behavior of Equilibrium Unemployment and Vacancies Revisited. American Economic Review, 98, 1692-1706. http://dx.doi.org/10.1257/aer.98.4.1692

[5] Pissarides, C. (2009) The Unemployment Volatility Puzzle: Is Wage Stickiness the Answer? Econometrica, 77, 13391369. http://dx.doi.org/10.3982/ECTA7562

[6] Eliaz, K. and Spiegler, R. (2013) Reference-Dependence and Labor-Market Fluctuations. NBER Working Paper No. 19085.

[7] Pissarides, C. (2000) Equilibrium Unemployment Theory. MIT Press, Cambridge.

[8] Compte, O. and Jehiel, P. (2003) Bargaining with Reference Dependent Preferences, Mimeo. 
Scientific Research Publishing (SCIRP) is one of the largest Open Access journal publishers. It is currently publishing more than 200 open access, online, peer-reviewed journals covering a wide range of academic disciplines. SCIRP serves the worldwide academic communities and contributes to the progress and application of science with its publication.

Other selected journals from SCIRP are listed as below. Submit your manuscript to us via either submit@scirp.org or Online Submission Portal.
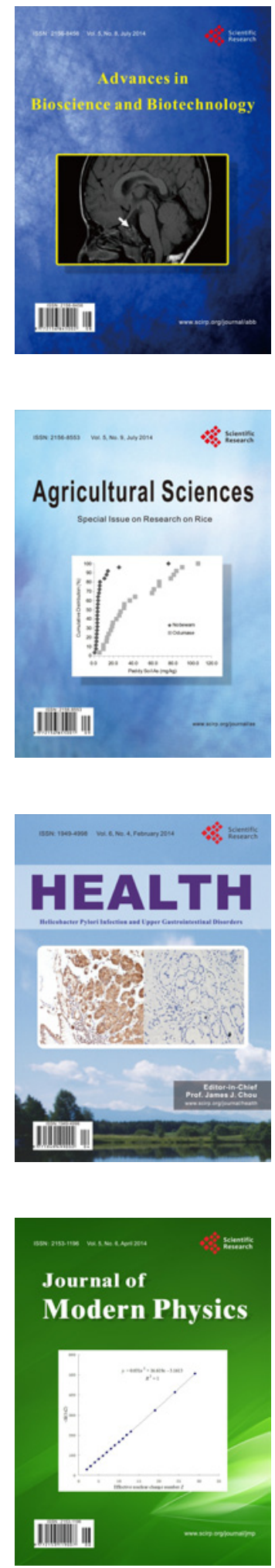
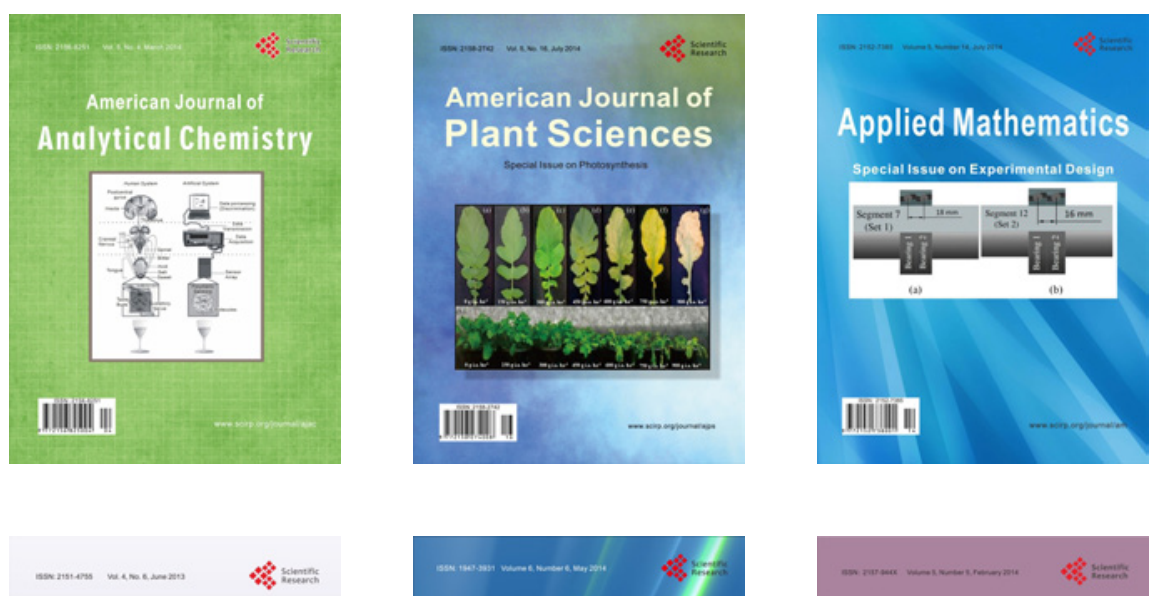

Creative Education
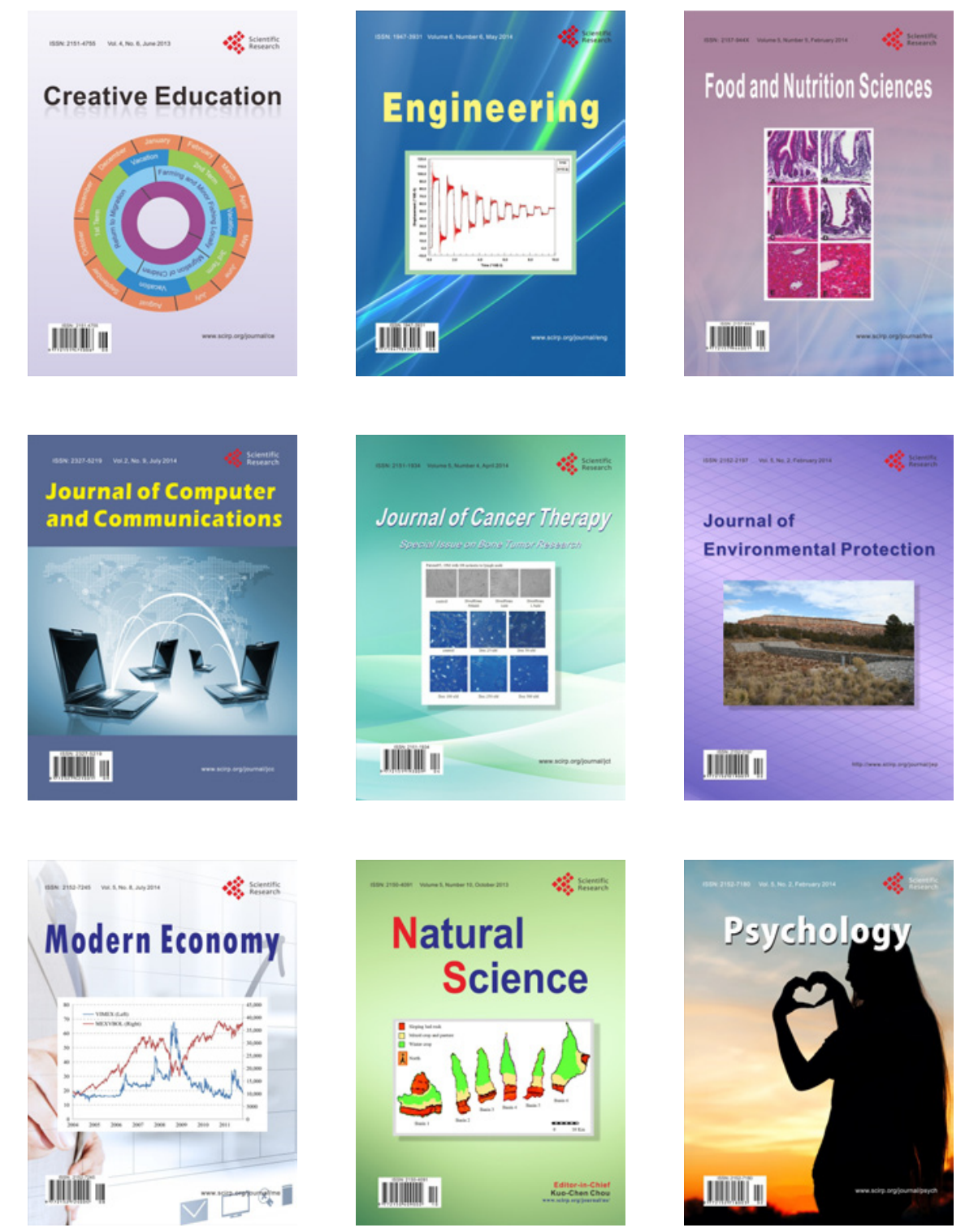